\title{
The Impact of Strategic Planning on Crisis Management Styles in the 5-star Hotels
}

\section{Karam Mohamed Ghazi}

\author{
Lecturer - Hotel Studies Department \\ The Higher Institute of Tourism and Hotels in Alexandria (EGOTH)
}

\begin{abstract}
:
This study investigates crisis management styles (escaping, confrontation, cooperation and containment) and their relationship to strategic planning processes in the 5-star hotels in Egypt. The study used descriptive analytical method, with qualitative and quantitative approaches. 190 self-administered questionnaires have been emailed to all the general managers at the Egyptian 5star hotels. Results indicated a statistically significant, effect-based correlation between strategic planning processes and crisis management styles, which was negative between strategic planning and escaping, while being positive between strategic planning and confrontation, cooperation, and containment. These findings implied the significant role of strategic planning in times of crises to improve hotels' ability to survive and thrive. Managers who actively exercise strategic planning are less escapable and more able to manage the crisis, either by using the styles of cooperation, confrontation or containment. Hence, hotels should employ a strategic approach to crisis management by embodying and integrating crisis management planning in the strategy setting process. Considering and planning for both simultaneously help managers think and plan strategically during the midst of crisis, and increase their ability to manage a crisis successfully.
\end{abstract}

Key Words: strategic planning, crisis, crisis management, crisis management styles.

\section{Introduction}

The tourism and hospitality industry is especially vulnerable to numerous types of crises including natural disasters, terrorist attacks, political instability, infectious diseases, industrial accidents, wars, economic recession, and so on. The happening of crises is on the rise and destinations will eventually encounter a serious crisis. A serious crisis can instantly harm a destination's image and infrastructure, as well as the country's economy (Pizam, 2010; Israeli et al. 2011; Wang and Ritchie, 2012; Jia et al., 2012; Speakman and Sharpley, 2012; Rittichainuwat, 2013; de Sausmarez, 2013; Mekinc and Cvikl, 2013; Becken, et al., 2014; Boukas and Ziakas, 2014; Ghaderi, et al., 2012, 2014, 2015; Purwomarwanto and Ramachandran, 2015; Granville, et al., 2016). Egypt is one of those countries that frequently encounter different crises such as Egyptian revolutions in 2011-2013, terrorist attacks, and political instabilities and wars from adjoining countries (Mohammad et al., 2012; Nassar, 2012). 
Despite of the vulnerability of the hospitality industry to the impacts of crises, numerous countries and destinations are relying on it for their development and survival (Speakman and Sharpley, 2012; Mair et al., 2016). This creates pressure on business directors to plan and think strategically during a crisis by managing both the positive opportunities and negative threats that a crisis consistently presents. Consequently, organizations need to plan for crisis concurrently as strategic planning, which have not yet been incorporated or integrated. Considering and planning for both at the same time increases the organization's ability to prevent, mitigate or manage a crisis successfully. Incorporating crisis management into strategic planning processes, and vice versa, improves the ability of organizations to not only survive, but also to thrive, both in good and crisis times (Brent, 2004; Vargo and Seville, 2011;_Lalonde, 2011; Pollard and Hotho, 2006; Wang et al., 2009; Groh, 2014).

The general research problem is that strategic planning and crisis management processes are typically carried out in isolation from each other, if they are ever done. It is essential to note that crises generally offer critical threats, associated with considerable opportunities. Those threats and opportunities should not be managed with a single discipline, but rather through dual-discipline approach; simultaneous crisis management and strategic planning. While crisis management focuses on opportunities, strategic planning focuses on threats. Otherwise, scattered crises handling efforts would else lead to a misuse of limited resources, and create a threat to the organization (Vargo and Seville, 2011; Lalonde, 2011).

The specific problem is that there is a research gap in the literature regarding the connection between strategic planning and crisis management. Though some literature promoted the integration of crisis management with strategic planning (Mitroff, et al., 1992; Boin and Lagadec, 2000; Brent, 2004; McConnell and Drennan, 2006; Pollard and Hotho, 2006; Wang et al., 2009; Vargo and Seville, 2011; Lalonde, 2011; Wang and Ritchie, 2012; Groh, 2014), but still, there is limited empirical research on the relationship between strategic planning and crisis management. In particular, there is a lack of empirical research that examines the relationship between strategic planning and crisis management in the hotel industry in general and in Egyptian hotels in particular. The current study filled this gap by examining crisis management styles and their relationship to strategic planning processes from of Egyptian hotel general managers' viewpoint.

Therefore, the research problem can be formulated through the following main question and its sub-questions: What are the styles of hotel crisis management, and what are their relation to strategic planning?

- What is the usage degree of hotel managers of crisis management styles (cooperation, confrontation, escaping, and containment)?

- What is the usage degree of hotel managers to hotel strategic planning processes?

- Is there statistically significant correlation relationship between the usage degree of both the crises management styles and the strategic planning processes?

- Is there statistically significant effect relationship of the usage degree of strategic planning on the usage degree of the crises management styles? 


\section{Objectives}

This study aimed to examine the relationship between strategic planning and crisis management styles as well as the impact of strategic planning on these styles from of hotel managers' viewpoint. The specific objectives are to:

1. Assess the usage degree of crisis management styles (cooperation, confrontation, escaping, and containment) from of hotel managers' viewpoint.

2. Assess the usage degree of strategic planning processes from of hotel managers' viewpoint.

3. Assess the relationship between the usage degree of crisis management styles and strategic planning processes.

4. Assess the influence of strategic planning processes on crisis management styles.

\section{Hypotheses}

As shown in Figure 1, this research has two major assumptions:

1. The first hypothesis has assumed the correlation relationship between strategic planning processes and crisis management styles (cooperation, confrontation, escaping, and containment). Hence, the null and alternate of Hypothesis 1 are:

$\square \mathbf{H}_{\mathbf{0}}$ - There is no a statistically significant correlation (at $\alpha \leq \underline{0.05}$ ) between the usage degree of crisis management styles and the strategic planning processes from hotel managers' viewpoint.

$\square \mathbf{H}_{1}$ - There is a statistically significant correlation (at $\alpha \leq 0.05$ ) between the usage degree of the styles of crises management and the usage of strategic planning processes from hotel managers' viewpoint.

2. The second hypothesis has assumed the influence of the strategic planning processes on the styles of crisis management (cooperation, confrontation, escaping, and containment). Hence, the null and alternate of Hypothesis 2 are:

$\square \mathbf{H}_{\mathbf{0}}$ - There is no a statistically significant effect (at $\alpha \leq 0.05$ ) of strategic planning in the usage degree of the styles of crises management from hotel managers' viewpoint.

- $\mathbf{H}_{2}$ - There is a statistically significant effect (at $\alpha \leq 0.05$ ) of strategic planning in the usage degree (utilization) of the styles of crises management from hotel managers' viewpoint.

Figure 1: The Hypotheses Model

Strategic Planning Processes (Independent)

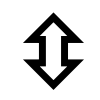

Crisis Management Styles (Dependent)

Cooperation Confrontation Containment

\footnotetext{
Effect Relationship (tested by Regression Analysis).
} 
Study Variables are:

1. Independent: strategic planning processes

2. Dependent: crisis management styles (escaping, cooperation, confrontation, and containment).

\section{Literature review}

\section{Crisis and Crisis Management}

Crisis management is defined as "the process that attempts to identify and predict areas of crises, the development of actions or measures designed to prevent crises from occurring, or from an incident evolving into a crisis, and minimizing the effects of disruption from a crisis that could not be prevented" (Preble, 1997, p. 773). As defined by Mogendorrf, (2008), crisis management is a means of proactively preparing a company for a worst-case scenario. It involves the careful planning of approaches that will minimize the effects on the operation in both short and long terms. According to Vargo and Seville (2011), crisis management is the discipline of preparing the resources and organizational structures necessary to respond effectively in the face of a crisis and recover effectively in the aftermath. It is about building the capability to identify imminent threats to the organization and designing a plan for addressing those threats. Crisis management is activities undertaken to plan prior to, manage during, and evaluate following a crisis (Wang and Ritchie, 2012).

However, crisis definitions are used in a certain context and explain a particular crisis, it is generally agreed that three elements are common to most crisis definitions: (1) a major threat to the survival of the organization, (2) the element of surprise and (3) a short decision time to respond (Seeger et al., 2003; Faulkner, 2001; Racherla and Hu, 2009). Moreover, majority of literature supports the view of crisis as a process rather than event, due to the evolving nature of a crisis. Subsequently, most crisis authors viewed crisis management as a process and most crisis management models are shaped around the different stages of a crisis. At least, crisis management can be divided into three phases: (1) Before-crisis (crisis planning), (2) During-crisis (crisisresponse), and (3) After-crisis (crisis evaluation and learning). Moreover, some authors further divided the phases into sub-phases (Coombs, 2012; Aba-Bulgu and Islam, 2007; Racherla and Hu, 2009; Wang and Ritchie, 2012; Ghaderi et al., 2012, 2014, 2015; Jia et al., 2012).

Most of the literature reflects on the threats and negative outcomes of crises. Yet, opportunities exist within any crisis (Burnett, 1998; Faulkner 2001; Mogendorrf, 2008; Vargo and Seville, 2011; Wang and Ritchie, 2012). Burnett (1998) presented seven crisis opportunities: (1) discovering new heroes; (2) accelerating changes; (3) facing latent problems; (4) changing people; (5) evolving new strategies; (6) developing early warning systems; and (7) appearance of new competitive edges. According to Mogendorrf, (2008), examples of positive opportunities include: narrowing the service concept to reinvent the product for today's/tomorrow's markets or (re)differentiate you product, refocus of market to attract different market segments, resizing or reducing your organization to a more manageable size, relocation to a safer environment, simplifying processes, 
combining activities or department for better customer service or cost control, update of assets, redefining of staff needs and skills, and staff retraining.

Overall, there are a variety of styles in order to deal with crises, including proactive and reactive approaches. In the proactive stance, the planning decisions take place before a crisis. Decision makers have already anticipated various forms of crises through vulnerability analyses and have developed plans to deal with its probability. In the reactive stance, the planning decisions take place during and after the crisis event. The main objective is containing the damage and the swift recovery of the status quo (Pearson and Mitroff, 1993; Hough and Spillan, 2005). In particular, there are four styles to deal with crises (Pearson and Mitroff, 1993; El-Mehdi and Hiba, 2002; Ahmad, 2002; Hilal, 2004; Abd-Elaal, 2008):

1. The escape style: is a negative style where the manager of the organization leaves the crisis and its impact completely, and recognizes the inability to cope with it, claiming that the reason for the weakness is in the staff performance.

2. The containing/containment style: where the manager reduces the spread and effect and of a crisis. The crisis is limiting and freezing at the stage reached by it, and work to absorb the pressures generated by it, and then destroyed by its destructive power.

3. The cooperation or teamwork style: where everyone in the crisis team cooperates in the face of the crisis and each member have specific duties.

4. The confronting style: where the organization manager with the help of his staff confronts the crisis in a scientific way based on good prediction and identification of roles and tasks, and move rapidly in all phases of the crisis to reduce the negative effects and return the organization to the state of stability it had.

\section{Strategic Planning}

Strategic planning is an essential requirement for the success of an organization by dealing with weaknesses and threats as well as the strengths and opportunities that present themselves to the organization (Preble 1997). Strategic planning is defined as "the process of formulating and implementing decisions about an organization's future direction. This process is vital to every organization's survival because it is the process by which the organization adapts to its everchanging environment, and the process is applicable to all management levels and all types of organizations" (Kerzner, 2001, p. 15). Boyle (2001, p.23) defined strategic planning as "a process that involves a) setting goals or objectives; b) assessing and forecasting the external environment; c) designing and assessing alternative courses of action, including analyzing the potential risks and rewards; d) selecting the best course of action; and e) evaluating results as the course of action is implemented". Strategic planning is a systematic planning process involving a series of steps to determine the current status of the business, including its mission, vision for the future, needs, objectives, actions and strategies' priorities, action plans and monitoring and evaluation programs. This process is a key component of strategic management (Sotirios and Nikolaos, 2016).

It should be noted there is a general agreement in the literature on viewing strategic planning as a process, i.e. the process of formulating, implementing, and evaluating strategy. Moreover, in the tourism sector, strategic planning is particularly a crucial process as has been found to be related 
to the performance of tourism enterprises. Strategic planning enables hotel companies to achieve both economic and non-economic objectives. Strategic planning is a critical factor for the effectiveness of strategic management (Sotirios and Nikolaos, 2016).

\section{The Relationship between Strategic Planning and Crisis Management}

Although strategic planning has developed as a discipline quite separate from crisis management; these two planning processes overlap considerably (Mitroff, et al., 1992; Preble 1997; Burnett, 1998; Pollard and Hotho, 2006; Vargo and Seville, 2011):

- They both deal with the organization's future,

- They both deal with the weaknesses (vulnerabilities) and threats (risks),

- They both involve processes to create, implement and evaluate plan,

- They both involve organizational structures and resources to carry out the plan, and

- They both require planning and adaptiveness along four enabling dimensions: leadership, culture, decision making and situation awareness.

It is clear from literature that organizations that want to perform well at both crisis management and strategic planning must:

- Be pre-planned to adapt to changing circumstances,

- Have leaders able to inspire their people with a sense of hope and direction,

- Have an organizational culture that values disciplined planning whilst fostering an ability to be creative and innovate,

- Plan and make decisions carefully in a structured way, yet be responsive and able to move quickly and boldly, and

- Have teams able to recognize patterns and integrate disparate information in order to make sense of a chaotic situation, while being sensitive and alert to subtle changes to the environment as the situation evolves.

The differences between strategic planning and crisis management are that the first focuses on opportunities, while the latter focuses on threats. Crisis management tends to focus on threats inherent in rapidly changing environments, while strategic planning focuses on the opportunities inherent in change. Yet both opportunities and threats are included in the uncertain future with which we have to deal (Mitroff, et al., 1992; Burnett, 1998). Crisis management focuses on improving the ability of organization to survive, while strategic planning focuses on improving the ability to thrive. Survival is the crisis management aspect, while thriving is the strategic planning aspect (Vargo and Seville, 2011). While strategic planning is frequently based on the assumption that tomorrow will be like today, crisis management is based on the adversity of tomorrow. In tourism environment, tomorrow is almost certainly not going to be like today. The integration of crisis management and strategic planning offers some considerable challenges as noted by Burnett (1998):

- Time pressure: crises may have to be dealt with immediately, while strategic planning normally would occur in time frames of months or even years. 
- Control: strategic planning normally assumes a reasonable control level over organizational processes and relationships, while a crisis may significantly inhibit such control.

- Threat magnitude and severity: in a crisis, the magnitude and severity of the threats can overwhelm management to such an extent that it prevents the formulation and implementation of strategy.

- Response options: strategic planning tends to maintain a range of options, the reality in a crisis may be that only one or a few options may be left to the organization to choose from.

In times of crisis, it is important to integrate crisis management with strategic planning to manage crises effectively. The result of the integration is that the organization is crisis-prepared and enjoying due resilience. Resilience is the ability of an organization not only to survive but also to thrive, both in good times and in the face of adversity. Considering and planning for both at the same time creates more robust planning and increases the organization's ability to mitigate, avoid or manage a crisis successfully. Through incorporating crisis management into an organization's strategic planning processes and vice versa, strategies can be developed to take advantage of these 'silver lining' opportunities in the midst of crises. Crisis strategic planning is a way of integrating the two concepts into one resilience planning process (Preble, 1997; Vargo and Seville, 2011; Groh, 2014). Preble (1997) stated that "adding crisis management's defensive preventative capability to strategic management's offensive market positioning orientation can yield a more comprehensive approach to strategic management of organizations".

\section{Methodology}

\section{Research Type and Approach}

A mixed-methods research design incorporating both quantitative and qualitative approaches was used in this study. The study used descriptive-analytical approach for its appropriateness to such studies to describe the phenomenon, to analyze data, and to identify the relationship between its components. Particularly, it used correlation method which aims to exploring the relationship between two variables (crisis management styles and strategic planning processes); that is, to determine the correlation between these variables and interpreting it into figures. Furthermore, this study used deductive approach, since it develops a theory and hypotheses and then designs a research strategy to test the validity of hypotheses against the data (this call a top-down approach) (Saunders et al., 2015). This study used two approaches for data collection; namely:

1. Desk Survey (Secondary Data Source). The desk survey (literature review) forms an essential aspect of the research since it sets the pace for the development of field survey instruments using questionnaires, and interview. Secondary sources of information were identified and collected from books, articles, professional periodicals, and databases on the subject of the study (Sekaran and Bougie, 2013).

2. Field Survey (Primary Data Source). The field survey is involved with the collection of empirical data. Fieldwork can be associated with three practical approaches; the survey approach, the case study approach and the problem-solving approach (action research). This research used the questionnaire technique that belongs to the survey strategy as the primary method of quantitative data collection. A self-administered questionnaire is used in this study. 
It means that this type of research is completed by respondents. In particular, the on-line email questionnaire method was used to collect data in order to test the hypotheses. The choice of e-mail questionnaire survey is mainly due to numerous benefits such as: obtaining relatively highest participation within a limited time frame, high confidence that right person has responded, ease of data coding, overcoming geographical limitations, minimizing expenses, and anonymity. By E-mail questionnaire, the researcher has time to reflect on the answers and keep continuous contact when questions arise (Dillman, 2000; Sekaran and Bougie, 2013; Saunders et al., 2015).

\section{Data Collection Instrument}

The questionnaire was built based on the conceptual framework drawn from the extant literature (Figure 1). Moreover, it was adapted and modified from previous developed scales to test crisis management styles and strategic planning in the hotel context. In particular, the final datacollection instrument consisted of two-parts:

- The first part measures the usage level of crisis management styles, consisting of 39 attributes representing 4 styles (escape, confrontation, cooperation, and containment). The participants were asked to indicate the degree of usage level of each attribute of crisis management styles, using a five-point Likert scale ranging from 1-very low to 5-very high.

- The second part measures usage level of the hotel strategic planning processes, consisting of 36 attributes. The participants were asked to indicate the degree of usage level of each attribute using a Likert scale ranging from 1-very low to 5-very high.

\section{Questionnaire Reliability, Validity and Objectivity}

Validity, reliability and objectivity can be seen as three dimensions of a study's credibility. Validity is the extent to which the data collection tool actually measures what it intended to measure from the beginning. Reliability is the degree of trust and if the result remains the same when being repeated. Objectivity is about the values of a researcher and how much it affects the results (Sekaran and Bougie, 2013; Saunders et al., 2015). The questionnaire was rationalized before being distributed to the study sample to ensure the validity and reliability of paragraphs:

1. To Verify Content Validity (Believe Arbitrators): At the early stage of this research, discussions with academic colleague and managers were carried out to collect information on the problem area. After which, the questions and measures of the variables in the questionnaire were drown from the intensive literature review. In particular, the first version of survey questionnaire was judged by a group of arbitrators through interviewing 5 experienced hotel managers and 5 academic professors in hotel studies. The arbitrators assessed language integrity, the appropriateness of the questionnaire attributes, and the affiliation of attributes to each of the dimensions of the questionnaire. Revisions to the questionnaire were made based on feedback from the arbitrators. The researcher responded to the views of the jury and performed the necessary deletions and modifications. Factors or questions with $80 \%$ approval and higher were only considered. The result was a revised version of the questionnaire with a smaller set of items. The changes made the statements more specific and easier to understand. 
2. To Verify Construct Validity: There are two types of analysis for determining construct validity: (1) Correlational analysis, and (2) Factor analysis (Sekaran and Bougie, 2013). This study calculated the construct validity of the attributes of the questionnaire by surveying it to the initial sample size of 15 respondents of the total members of the study population. It calculates the Pearson correlation coefficients between the degree of each dimension of the questionnaire and the total degree for the questionnaire (structure validity). It also calculates the Pearson correlation coefficients between each attribute of the questionnaire and the total degree for the domain dimension that belongs to him that attribute (internal validity). The results indicated that all attributes and dimensions are statistically significant (at $\alpha \leq 0.01$ and $\alpha \leq 0.05$ ), which confirm the internal consistency (validity) of the questionnaire.

3. To Verify Reliability: The most popular test of inter-item consistency reliability is Cronbach's coefficient alpha (Sekaran and Bougie, 2013). The researcher conducted reliability steps on the same initial sample using Cronbach's alpha coefficient. The study calculated alpha coefficient for each dimension of the questionnaire as well as for the total questionnaire. The results indicated that alpha coefficients of all dimensions and total alpha coefficient for questionnaire are above 0.61, which indicating satisfactory internal consistency; giving the research the reliability to applying the questionnaire to sample study. The strong internal consistency reliability for the revised scales indicated that the retained items measure the same constructs, suggesting the possibility of the stability of the results that can result from the tool. Thus, the questionnaire became valid and reliable in its final form for application to the basic study sample.

\section{Sampling Plan and Procedures}

The target population of this study was the general managers at the Egyptian five-star hotels. Comprehensive sample was chosen as the most appropriate sampling technique to get a big sample and thus ensure that the results are significant and generalizable. The surveys were directed at senior level managers due to the nature of their role as chief executive decision-makers in the event of hotel crisis incidents and long future strategic plans. Moreover, only 5-star hotels were chosen due to that big hotels have the resources and education to properly implement strategic planning and crisis management process.

The surveyor telephoned each hotel in the sample and requested the e-mail of the general manager or the highest-ranking manager in cases where there was no such manager. The surveyor sent him (or her) a self-administrated e-mail questionnaire. To increase response rate, the surveyor sent another two e-mail reminders for managers who don't respond the first e-mail. In March 2017, a total of 190 self-administrated e-mail questionnaires were distributed to hotel managers in 190 five-star hotels in Egypt. 138 questionnaires were returned, resulting in a $73 \%$ response rate. 15 were not included because of incompleteness. The valid number of questionnaires for analysis was 123 with response rate was $65 \%$.

For ethical considerations and adequate response rate, the questionnaire was accompanied by a covering letter that emphasized the significance of the issue under investigation, but also stressed that participation in the study was voluntary. As noted by Dillman (2000), the covering Letter 
affects the response rate. At the beginning of questionnaire, there was a brief explanation of the purpose of the survey, the importance of the respondent participation and respondent confidentiality. The respondents were advised that the data collected would be used solely for the purpose to address the research topic. There were no anticipated risks to the respondents who participated in the study. The removal of any personal identifying information or data was the means to maintain confidentiality. At the end of the questionnaire it was explained what the respondent need to do with a completed questionnaire.

\section{Data analyses}

Analysis of the gathered data used the software SPSS 19.0 (Statistical Package for Social Sciences) and Microsoft Excel 2010. The principal statistical tool utilized was the non-parametric statistical testing using descriptive statistics, Person correlation and Regression analysis. Objective 1 and 2 were achieved by descriptive statistics. Objective 3 and hypothesis 1 were achieved by Person Correlation Analysis. Objective 4 and hypothesis 2 were achieved by Regression analysis. Finally, interpretation of the results was done at $5 \%$ level of significance; where the value of $\mathrm{p} \leq$ 0.05 was considered as being significant, and $\mathrm{p} \leq 0: 01$ was considered as being highly significant.

\section{Operational Definitions of Key Terms}

Strategic planning: is the process of formulating, implementing, and evaluating decisions about a hotel's future direction. This process involves a) setting goals or objectives; b) assessing and forecasting the external environment; c) designing and assessing alternative courses of action, including analyzing the potential risks and rewards; d) selecting the best course of action; and e) evaluating results as the course of action is implemented.

Crisis: is a low probability, high impact event that threatens the viability of the hotel and is characterized by ambiguity of cause, effects and means of resolution, as well as by a belief that decisions must be made swiftly.

Crisis Management: is the process of planning prior to, managing during, and evaluating following a crisis. This process involves identifying and predicting areas of crises, the development of actions or measures designed to prevent crises from occurring, or from an incident evolving into a crisis, and minimizing the effects of disruption from a crisis that could not be prevented.

Styles of Crisis Management: The strategies, activities and procedures used by the hotel manager in managing the hotel crisis, namely escape, cooperation, confrontation, containment.

\section{Results}

\section{The Usage Degree of Crisis Management Styles (Objective 1)}

Table (1) indicated that the "Containment" style ranked first with a mean of (3.83) and a relative weight of (76.6). This finding implied that hotel managers perceived this style as the top priority 
and widely used style in crisis management. The top usage priority of this style can be explained by the fact that the survey was conducted during the significant effects of the Egyptian political instability, where the top concern of hotel managers has been to contain the crisis from its inception and limit it to a minimum. The highest attribute in this style has been "Work on limiting the crisis in a limited scope inside the hotel so as not to spread" with a mean score of (3.91) and relative weight of (78.2\%). Meanwhile, the less attribute is "Work on not spreading rumors and exaggerations in talking about the crisis so as not to exacerbate their occurrence"' with a mean score (3.77) and relative weight (75.4\%).

Table 1: Descriptive Statistics of Strategic Planning Processes and Crisis Management Styles ( $=$ 123)

$\begin{array}{llllll}\text { Variables } & \text { Measures } & \text { Mean } & \begin{array}{l}\text { Standard } \\ \text { Deviation }\end{array} & \begin{array}{l}\text { Relative } \\ \text { Mean Weight }\end{array} & \text { Rank } \\ & \text { Escaping (10 attributes) } & 3.74 & 0.596 & 74.8 & 2 \\ \text { Dependent } & \text { Cooperation (10 attributes) } & 3.54 & 0.621 & 70.8 & 3 \\ \text { Variable } & \text { Confrontation (10 attributes) } & 3.48 & 0.624 & 69.6 & 4 \\ & \text { Containment (9 attributes) } & 3.83 & 0.581 & 76.6 & 1 \\ \text { Independent } & \text { Strategic Planning processes } & 4.12 & 0.547 & 82.4 & - \\ \text { Variable } & \text { (36 attributes) } & & & & \end{array}$

This is followed by the "Escape" style, where it ranked second with a mean of (3.74) and a relative weight of $(74.8 \%)$. This implied that hotel managers perceived this style as the number two of usage priority and second widely used style in crisis management. This indicates that some hotel managers recognize the inability and failure to face the crisis because of the strength of political circumstances and increasing its impact, fear of failure in the face of crisis, or lack of resources or powers granted to face the crisis. Therefore, they resort to escape from the crisis in different forms, such as hiding and denying the crisis, leaving the area of the crisis and its impact, putting blame on others, justifying the causes of the crisis, focusing on other defects and inadequate performance, the media blackout on the crisis, or demonstrating the safety of the position, good performance, and that the crisis has been controlled. The highest attribute in this style is "Political circumstances prevent me from the face of the crisis" with a mean score of (3.82) and relative weight of (76.4\%). Meanwhile, the less attribute is "Pretend that the hotel controlled the crisis, and the hotel at its best" with a mean score (3.69) and relative weight (73.8\%).

Then the "Cooperation" style ranked third with a mean of (3.54) and relative weight of (70.8\%). This confirms that some managers are aware of the importance of the cooperation of all hotel staff in the face of crises, since it is not only the director alone can effectively confront the crisis. The highest attribute in this style is "Consult the people of opinion, knowledge, and experience in dealing with hotel crises" with a mean score of (3.63) and relative weight of (72\%). Meanwhile, the less attribute is "Coordinate the efforts of the hotel employees and the bodies and authorities outside the hotel which can cooperate with them in controlling the crisis" with a mean score (3.47) and relative weight (69.4\%). 
Finally, the "confrontation" style ranked fourth with a mean of (3.48) and relative weight of (69.6\%). This finding implied that hotel managers perceived this style as the less usage priority and rarely used style in crisis management. This indicates that hotel managers' performance in utilizing the confrontation style is low. Hence, hotel managers should concentrate on this style, and more resources, effort and attention should be spent on improving this style. It also indicates that hotel managers do not face crises in a scientifically based way. Hotel managers must stay away from random and reaction policies in the face of crises. Rather, they must follow the scientific and proactive planning approach to face crises by predicting and preventing the expected crises, designing advance scenarios and plans of confrontation, finding the priorities agenda, forming crisis team with required resources, designing an effective crisis communications and information system, quickly gathering sufficient and accurate information on the crisis specifying the necessary resources and capabilities to confront the crisis, define the responsibilities of the participants in confronting the crisis, harmony and complementarity between the various efforts exerted to confront the crisis, crisis assessment and follow-up, and learning lessons from the current crisis to prevent their occurrence in the future. Managers must plan ahead what needs to be done in confronting crises, how to do it, when, who to do, predict events and draw scenarios. The highest attribute in this style was "Put a comprehensive plan to address the crisis" with a mean score of (3.52) and relative weight of (70.4\%). Meanwhile, the less attribute was "Specify the necessary resources and capabilities to cope with the crisis", with a mean score of (3.46) and relative weight of $(69.2 \%)$. Hotel managers use the style of confrontation in crises management with a mean of (3.48) and a relative weight of (69.6\%).

Overall, the rankings in descending order of the usage mean of crisis management styles were as follow: Containment (3.83), Escaping (3.74), Cooperation (3.54), and Confrontation (3.48).

\section{The Usage Degree of Strategic Planning Processes (Objective 2)}

It is clear from Table (1) that hotel managers used strategic planning processes with a mean of (4.12) and a relative weight of $(82.4 \%)$. This finding implied that the overall usage score of the strategic planning processes was relatively high. The researcher attributed this relatively high usage to the fact that hotel managers feel the important role of strategic planning in business success and ensure the performance and effectiveness of hotel enterprises. It enables hotel companies to achieve both economic and non-economic objectives. It is a critical factor for the effectiveness of Strategic Management. Previous studies confirmed this result (Grant, 2008; Sotirios and Nikolaos, 2016).

The highest attribute was "The hotel's message shall be clearly and accurately formulated." It was ranked first with a mean of (4.31) and a relative weight of (86.2\%). This finding implied that hotel managers understand that the clarity and accuracy of the message help them achieve the desired goals and objectives, as they reflect the philosophy, ambition and purpose of the hotel. The lowest attribute is "The hotel vision is consistent with the vision of the Ministry of Tourism" with a mean score (3.82) and a relative weight of (76.4\%). This finding implied that hotel managers considered that their hotels' vision isn't consistent with the vision of the Egyptian Ministry of Tourism. This indicated the lack of coordination between Egyptian tourist institutions, and the lack of 
consolidation of future strategic objectives. Hotel managers stay away from the Ministry of Tourism. As the Egyptian Ministry of Tourism is responsible for following up the work in the hotels and tourist destinations, so managers must pay attention and care to ensure that there is no conflict or difference in the two visions, and coordination between them is necessary. Managers must take into account the harmony and consistency of their hotels' vision with the vision of the Egyptian Ministry of Tourism. The coordination between the two visions facilitates the achievement of future goals in an effective manner. Overall, the achievement of the objectives/goals of hotels and tourist institutions lead to the achievement of the objectives of the Egyptian Ministry of Tourism. The vision must be harmonized between the tourism institutions and the tourism ministry to unify efforts and reach the desired future goals. Volgger and Pechlaner (2014) identified collaboration among tourism stakeholders as the key for destination managers to achieve competitiveness.

\section{The Relationship between Crisis Management Styles and Strategic Planning Processes (Objective 3 / Hypothesis 1)}

Table (2) shows that there is a statistically significant positive correlation (at $\alpha \leq 0.01$ ) between the styles of hotels crisis management (confrontation, cooperation, and containment) and hotel strategic planning, where Pearson correlation is $(0.62,0.55,0.33)$ respectively. There is also a statistically significant negative correlation $(\alpha \leq 0.01)$ between the style of escape and the hotel strategic planning where Pearson correlation is $(-0.25)$. The highest correlation was found with the style of confrontation, then cooperation, followed by containment.

Testing hypothesis 1: Since, the correlations are all statistically significant (at $\alpha \leq 0.01$ ). Hence, the null hypothesis 1 which proposed an absence of relationship was therefore rejected. Meanwhile, the alternate hypothesis 1 which proposed an existence relationship, was therefore accepted. This finding indicated that there is agreement between hotel managers on the significance role of strategic planning in crisis management styles (confrontation, cooperation and containment) in the Egyptian 5-star hotels. There is a certain level of consistency in the behavior of managers.

Table 2: The correlation and regression between strategic planning and crisis management styles

\begin{tabular}{|cccccc|}
\hline & \multicolumn{5}{c}{ Strategic Planning } \\
Crisis Management Styles & \multicolumn{4}{c}{ Pearson Correlation } & Regression \\
& $\mathrm{R}$ & Sig & $\mathrm{F}$ & $\mathrm{R}^{2}$ & $\mathrm{Sig}$ \\
\hline Confrontation & 0.62 & 0.000 & 18.62 & 0.188 & 0.000 \\
Cooperation & 0.55 & 0.000 & 16.43 & 0.165 & 0.000 \\
Escaping & -0.25 & 0.01 & 4.54 & 0.048 & 0.01 \\
Containment & 0.33 & 0.002 & 9.32 & 0.096 & 0.002
\end{tabular}

Assessing the Effect of Strategic Planning Processes on Crisis Management Styles 
It is clear from Table (2) that the independent variable (strategic planning) has achieved a significant effect relationship with the four dependent variables (confrontation, cooperation, containment, and escape) at the level of significance (at $\alpha \leq 0.01$ ), where the values of $F$ for each were $(18.62,16.43,9.32,4.54)$ respectively, which is more than the spreadsheet value with (0.000), (0.000), (0.002), (0.01) respectively. As well as the value of $\mathrm{R}^{2}$ reached (0.18) (0.16) (0.096) (0.048), indicating that independent variable (strategic planning) explains $18 \%$ of the changes in the dependent variable (confrontation style), $16 \%$ of the changes in the dependent variable (cooperation style), $9 \%$ of the changes in the containment style, and $5 \%$ of the changes in the escape style. This result implied that strategic planning plays a significant role in managing crises. This means that strategic planning contributes to and helps confront the crisis, contain the damage caused by the crisis, and help effective cooperation between participants in the face of crises.

Testing hypothesis 2: Since the independent variable (strategic planning processes) significantly affected the four dependent variables (confrontation, cooperation, containment, and escape), therefore the null hypothesis 2 which proposed an absence of effect, the relationship was therefore rejected. Meanwhile, the alternate hypothesis 2 which proposed an existence effect relationship, was therefore supported. This result implied the existence of a significant effect of the strategic planning processes in the styles of crisis management, and this is consistent with the relationship achieved in the first hypothesis.

\section{Conclusion}

The vulnerability of the tourism and hospitality industry to the impacts of crises increases the responsibility of tourism and hotel managers to plan and think strategically in times of a crisis to manage crisis successfully. Therefore, this study investigates crisis management styles and their relationship to strategic planning process in the 5-star hotels. This study used descriptive analytical method with qualitative and quantitative approaches. 190 self-administered e-mail questionnaires are sent to the general managers at the Egyptian five-star hotels. Using Pearson correlation and regression analysis, the results indicated that there is a statistically significant correlation and effect relationship (at $\alpha \leq 0.01$ ) between the strategic planning processes and crisis management styles, which was negative between strategic planning and escape, and was positive between strategic planning, and confrontation, cooperation and containment. This finding implied the significance role of strategic planning in crisis management styles (confrontation, cooperation and containment) in the Egyptian 5-star hotels.

The study results are considered logical since the manager who actively exercises strategic planning is less escapable and more able to manage the crisis, either by using the method of cooperation, confrontation or containment. The clarity of vision and the identification of the hotel's mission and objectives accurately and analyzing the internal environment to know the strengths to strengthen and weaknesses to address them, as well as analysis of the external environment to know the opportunities available to exploit well and identify external threats to overcome them, all helps the hotel manager not to escape the crisis and face them with full force and to benefit from them in the future and to work to avoid recurrence. 
This study promotes the relationship between strategic planning and crisis management styles to improve hotels' ability to survive and thrive in a crisis. The study sees strategic planning as the basis for crisis management. It contributes to preventing the crisis and overcoming the element of surprise. It also provides the opportunity for the crisis management team to confront the crisis in a scientific and organized manner away from randomness. Through strategic planning, time and available resources can be effectively exploited and invested to the fullest to deal with the crisis if they occur.

\section{Recommendations and Implications}

This study is one of the first studies to correlate crises management styles to strategic planning processes, not only in the hotel industry, but also in Egyptian five-star hotels. This research contributed to the theoretical and practical approach of the field of tourism strategic crisis management. It provides useful advice to hotel and tourism managers and organizations, hotel associations, and hotel studies researchers. The study recommends the following:

1. The main practical implication for this study is that hotel and tourism managers should consider the significance role of strategic planning in times of crises and its relation to styles of crisis management. Hotels and managers should be working on making crisis management as an integral and integrated part with strategic planning. Hotels should employ a strategic approach to crisis management by embodying crisis management processes and planning in the strategy process. The study promotes the incorporation of crisis management processes in a hotel's strategy process. This helps increase the effectiveness of managing crises and improving the strategic performance of hotels. Considering and planning for both at the same time helps hotels think and plan strategically during the midst of crisis and increases their ability to manage a crisis successfully. Promoting the adoption of strategic crisis planning is one method to integrate the two disciplines because it increases the effectiveness of hotel managers in dealing with crises.

2. Coordinating the efforts of hotels and government agencies and external institutes which can cooperate to manage hotel and tourism crisis. Creating a specialized crisis management department in ministry of tourism and joining it with crisis management team in each hotel and tourism business. Destination managers should enhance collaborative efforts with various tourism stakeholders (public and private sectors, not-for profit organizations, and local communities) as the key to achieve competitiveness. Building and promoting effective communication system between tourism partners is vital to ensure the speed and availability of information necessary for effective dealing with tourism and hotel crises.

3. Ministry of Tourism, Ministry of Higher Education, and other scientific research institutions should focus on research and studies related to strategic crisis management in tourism in general and in hotels in particular (more intention and care). Conducting annual conferences about crisis management and its relation to strategic planning. Teaching crisis management and strategic planning courses in faculties of tourism and hotels is also a necessity.

4. It is necessary to hold training courses, workshops, and train-the-trainer programs to hotel managers and employees (the Egyptian hotel union members) on strategic planning and its importance role in improving hotels and crises planning. 
5. Qualifying and recruiting efficient human resources leaders to prepare future proactive crisis management plans and preparing crisis scenarios of management.

6. Tourism Ministry and hotel associations should prepare an annual report on the crises that occurred in hotels to be used in the management of future crises. Tourism Ministry and hotel associations should provide each hotel manager with a manual that includes some types of hotel crises that occurred before and how they were dealt with effectively.

\section{Future research}

Additional research may extend knowledge from the findings of this study:

- Studying how crisis management could be integrated into the hotel's strategic planning process to enhance organizational resilience. There is limited empirical research on the way to integrate crisis and strategic planning to build organizational resilience.

- Studying the relationship between hotel leadership styles and crisis management.

- Studying how crisis planning and strategic planning processes differ by organizational and environmental factors, such as organizational culture, regions and types of crises. Examining the organizational and environmental factors that influence crisis planning intentions and behaviors.

- Studying recovering destination image and post-crisis destination marketing strategies.

- Investigating barriers and difficulties of tourism leaders in devising crisis management methods and plans,

- Studying the effect of information, communication, and media relations strategies in crisis management.

- Studying crisis learning feedback as one of the important ways organizations can integrate strategic and crisis planning.

- Studying the relationship between strategic planning, crisis planning and resilience to ensure sustainable competitive advantage in a tourism environment.

\section{Study Scope and Limitations:}

1. The objective limit: the objective of the study was limited to the four styles of crisis management (cooperation, confrontation, escaping, and containment) and determining the relationship between each style and the usage degree of hotel strategic planning processes (from 5-star hotel managers' viewpoint).

2. The spatial limit (place limitation): the study applied in Egypt region.

3. Institutional limit: this study was limited to only the Egyptian 5-star hotels that are typically members of the Egyptian Hotel Association (EHA) (Egyptian Hotel Guide 2010-2011). Generalizations are limited to only those hotels who decided to participate in this study.

4. The human limit (Respondent limit). The study was limited to the top (general) managers of 5-star hotels.

5. The time limit: The study was conducted during March 2017. 


\section{References}

Aba-Bulgu, M., and Islam, S. (2007) Corporate Crisis and Risk Management: Modeling, Strategies and Sme Application. Amsterdam, The Netherlands: Elsevier LTD.

Abd-Elaal, R. (2008) Methods of Crises Management to Public Schools Principals in Gaza Governorates and their Relationship to Strategic Planning. Master Thesis, Islamic University, Faculty of Education, Educational Administration Department, Palestine

Ahmed, A. (2002) Educational Crisis Management in Schools: Causes and Treatment. Cairo: Dar El Fekr El-Araby.

Becken, S., Mahon, R., Rennie, H., and Shakeela, A. (2014) 'The tourism disaster vulnerability framework: An application to tourism in small island destinations', Natural Hazards, 71(1), 955-972.

Boin, A. and P. Lagadec (2000) 'Preparing for the future: critical challenges in crisis management', Journal of Contingencies and Crisis Management. 8(4), 185-191.

Boukas, N., and Ziakas, V. (2014) 'A chaos theory perspective of destination crisis and sustainable tourism development in islands: The case of Cyprus', Tourism Planning and Development, 11(2), 191-209.

Boyle, P. (2001) 'From strategic planning to visioning: Tools for navigating the future', Public Management, 83(4), 23-28.

Brent, W (2004) 'Chaos, crises and disasters: A strategic approach to crisis management in the tourism industry', Tourism Management, 25, 669-683.

Burnett, J. (1998) 'A strategic approach to managing crisis’, Public Relations Review, 24(4), 475-484.

Coombs, T. (2012) Ongoing Crisis Communication. (3rd ed.) Thousand Oaks, CA: SAGE Publications, Inc.

de Sausmarez, N. (2013) 'Challenges to Kenyan tourism since 2008: crisis management from the Kenyan tour operator perspective', Current Issues in Tourism, 16(7/8), 792-809.

Dillman, D. A. (2000) Mail and Internet Surveys: The Tailored Design Method (Vol. 2.). New York: Wiley.

El-Mahdi, S., and Hiba, H. (2002) 'Behavioral practices of school managers in dealing with crises inside the school', Journal of the Faculty of Education and Psychology, 26(4), 221-143. (Arabic reference).

Faulkner, B., (2001) 'Towards a framework for tourism disaster management', Tourism Management, 22(2), 135-147.

Ghaderi, Z., Som, A. P. M., and Henderson, J. C. (2015) 'When disaster strikes: The Thai floods of 2011 and tourism industry response and resilience', Asia Pacific Journal of Tourism Research, 20(4), 399-415.

Ghaderi, Z., Som, A. P. M., and Wang, J. (2014) 'Organizational learning in tourism crisis management: An experience from Malaysia', Journal of Travel and Tourism Marketing, 31(5), 627-648.

Ghaderi, Z., Som, A., and Henderson, J. (2012) 'Tourism crises and island destinations: Experiences in Penang, Malaysia', Tourism Management Perspectives, 2-3, 79-84.

Granville, F., Mehta, A., and Pike, S. (2016) 'Destinations, disasters and public relations: Stakeholder engagement in multi-phase disaster management', Journal of Hospitality and Tourism Management, 28, 73-79.

Groh, M. (2014) 'Strategic management in times of crisis', American Journal of Economics and Business Administration, 6(2), 49-57.

Hilal, M. (2004) Crisis Management Skills: The Crisis Between Prevention and Control. The Center for The Development of Performance and Development. ( $4^{\text {th }}$ ed.) Cairo (Arabic reference).

Hough, M., and Spillan, J. (2005) 'Crisis Planning: Increasing Effectiveness, Decreasing Discomfort', Journal of Business \& Economics Research, 3(4), 19-24.

Israeli A., Mohsin, A., and Kumar, B. (2011) 'Hospitality crisis management practices: The case of Indian luxury hotels', International Journal of Hospitality Management, 30(2), 367-374.

Jia, Z., Shi, Y., Jia, Y., and Li, D. (2012) 'A framework of knowledge management systems for tourism crisis 
management', Procedia Engineering, 29, 138-14 3.

Kerzner, H. (2001) Strategic Planning for Project Management Using a Project Management Maturity Model. New York: John Wiley \& Sons, Inc.

Lalonde, C. (2011) 'Managing crises through organizational development: A conceptual framework', Disasters, 35(2), 443-464.

Mair, J., Ritchie, B. W., and Walters, G. (2016) 'Towards a research agenda for post- disaster and post-crisis recovery strategies for tourist destinations: A narrative review', Current Issues in Tourism, 19(1), 1-26.

McConnell, A. and L. Drennan (2006) 'Mission impossible? Planning and preparing for crisis', Journal of Contingencies and Crisis Management, 14(2), 59-70.

Mekinc, J., and Cvikl, H. (2013) 'The structure of security and safety crises in tourism', Journal of Tourism and Services, 5, 38-50.

Mitroff, I., Pearson, C., and Pauchant, T.C. (1992) 'Crisis management and strategic management: similarities, differences and challenges’, Advance in Strategic Management, 8, 235-260.

Mogendorff, D. A. (2008) Crisis management. In, Jones, P., and Pizam, A. (edit.), Handbook of Hospitality Operations and IT, Butter Worth-Heinemann Publications, Elsevier LTD.

Mohammad, A., Jones, E., Dawood, A., and Sayed, H. (2012) 'The Impact of the Egyptian political events during 2011 on hotel occupancy in Cairo', Journal of Tourism Research \& Hospitality, 1(2), 1-8.

Nassar, M. A. (2012) 'Political Unrest Costs Egyptian Tourism Dearly: An Ethnographical Study', International Business Research, 5(10), 166-174.

Pearson, C., and Mitroff, I. (1993). From crisis prone to crisis prepared: A framework for crisis management', Academy of Management, 7(1), 48-59.

Pizam, A., (2010) 'Hotels as tempting targets for terrorism attacks', International Journal of Hospitality Management, 29(1), 1-196.

Pollard, D. and Hotho, S., (2006). Crises, scenarios and the strategic management process. Management Decision, 44(6), 721-736.

Preble, J. (1997) 'Integrating the crisis management perspective into the strategic management process', Journal of Management Studies, 34(5), 769-791.

Purwomarwanto, Y. L., and Ramachandran, J. (2015) 'Performance of tourism sector with regard to the global crisis: A comparative study between Indonesia, Malaysia and Singapore', Journal of Developing Areas, 49(4), 325-339.

Racherla, P. and Hu, C.A. (2009) 'Framework for knowledge-based crisis management in the hospitality and tourism industry. Cornell hospitality Quarterly, 50(4), 1-17.

Rittichainuwat, B. (2013) 'Tourists' and tourism suppliers' perceptions toward crisis management on tsunami', Tourism Management, 34(1), 112-121.

Saunders, M., Lewis, P., and Thornhill, A. (2015) Research Methods for Business Students. (7 ${ }^{\text {th }}$ ed.) Pearson, Inc.

Seeger, M., Sellnow, T., and Ulmer, R. (2003) Communication and Organizational Crisis. Westport, CT: Praeger Publishers.

Sekaran, U., and Bougie, R. (2013). Research Methods for Business: A Skill Building Approach, Chichester: John Wiley \& sons.

Sotirios, V., and Nikolaos, G. (2016) Measurement of Strategic Management Effectiveness in Tourism Enterprises. In: International Conference on "Business, Economics, Social Science \& Humanities'” BESSH-2016, Proceedings of a conference, Sydney, Vol. 146- Issue.3, 41-45.

Speakman, M., \& Sharpley, R. (2012) 'A chaos theory perspective on destination crisis management: Evidence from Mexico', Journal of Destination Marketing and Management, 1(1), 67-77. 
Vargo, J., and Seville, E. (2011) 'Crisis strategic planning for SMEs: finding the silver lining, International Journal of Production Research', 49(18), 5619-5635.

Volgger, M. and Pechlaner, H. (2014) 'Requirements for destination management organizations in destination governance: Understanding DMO success', Tourism Management, 41, 64-75.

Wang, J. and Ritchie, B. W. (2012) 'Understanding accommodation managers' crisis planning intention: An application of the theory of planned behavior', Tourism Management, 33, 1057-1067.

Wang, J., Hutchins, H., and Garavan, T. (2009) 'Exploring the strategic role of human resource development in organizational crisis management', Human Resource Development Review, 8(1), 22-53. 